Iranian Journal of Applied Linguistics (IJAL), Vol.18, No.1, March 2015, 65-94

\title{
Proceduralization and Transfer of Linguistics Knowledge as a Result of Form- focused Output and Input Practice
}

\section{Mehrnoosh Fakharzadeh*}

Assistant Professor of Applied Linguistics, Sheikhbahaee University, Isfahan, Iran

\section{Manijeh Youhanaee}

Assistant Professor of Language and Linguistics,
University of Isfahan, Isfahan, Iran

Received 2 January 2014; revised 18 December 2014; accepted 28 January 2015

\begin{abstract}
This study compared the effects of two types of form-focused tasks on proceduralization and transfer of linguistics knowledge in case of English modals. All participants of the study attended pretests, posttests and delayed posttests. The procedural comprehension and production knowledge were measured through the groups' performance on a timed dual task test that resembled the context of practice. The transfer of knowledge was measured by evaluating the performance of participants on a timed dual task test in a context dissimilar from or reverse to the practice context.
\end{abstract}

Email address: mfakharzade@shbu.ac.ir

Corresponding Address: English Language Department, Faculty of Foreign

Languages, Sheikhbahaee University, Olfat St. Baharestan, Isfahan, Iran. P.O. Box:

81431-53784 Phone number: +98 3136803772 
Three intact classes of intermediate EFL learners were randomly assigned to experimental and control groups. The output group $(n=27)$ received explicit grammar instruction and a combination of three output practice, while the input group $(n=25)$ received explicit instruction and a combination of three input practice. Identical texts were exposed to the control group $(n=25)$ through listening and reading tasks. The texts were followed by some questions irrelevant to English modals. On the procedural knowledge posttests, the experimental groups outperformed the control group. The participants were able to transfer the knowledge to dissimilar contexts. The results may help language teachers design more effective activities for the learners considering the institutional constraints.

Keywords: Declarative knowledge; Proceduralization; Input practice; Output Practice; Transfer of knowledge

\section{Introduction}

Language teaching methodology has witnessed fluctuations in its emphasis on different types of knowledge and learning from a psychological point of view. The Grammar Translation Method was a pure representation of explicit teaching and learning without the slightest emphasis on implicit/procedural knowledge acquisition (Dornyei, 2009). Viewing language learning as the formation of correct language habits and over-learning of a range of stimulus-response chains, the Audio-Lingual Method made an effort to promote implicit learning and automatization (Dornyei, 2009). The standard Communicative Language Teaching (CLT), similarly, relied on a purely implicit learning and procedural knowledge. This knowledge was assumed to be acquired through the learners' participation in meaningful second language interactions rather than drilling and memorization. However, the standard CLT fell into disfavor because a purely implicit/procedural learning failed to yield competent and fluent language learners (Spada, 2007). Consequently, later versions of CLT highlighted explicit/declarative and direct elements, hence locating CLT within the cognitive model of learning (Johnson \& Johnson, 1998). 
Perhaps the most widely accepted cognitive model of acquisition has been ACT (Adaptive Control of Thought) and ACT-R (Adaptive Control of Thought Reaction) skill acquisition models (Segalowitz, 2005) developed by Anderson (1983) as well as Anderson and Lebiere (1998). The models draw heavily on the duality of knowledge base, i.e. the distinction between declarative and procedural knowledge. While declarative knowledge is concerned with knowing the facts, procedural knowledge is practical in that it is associated with knowing how to do things. Given that language can be considered as a skill, the model has been applied to SLA, where declarative knowledge implies knowledge about the system and procedural knowledge refers to knowledge on how to use it (DeKeyser, 1997, 1998).

Disagreement exists as to whether there is any interaction between declarative and procedural knowledge sources. Krashen (1981) and VanPatten (1996) adopted a non-interface position (i.e., arguing they did not interact), whereas others, such as Ellis (1993) and N. Ellis (2005) have argued for an interface position. The nature of this interface is a point of further controversy. Whereas supporters of a 'skilllearning theory' of L2 acquisition (e.g., Anderson, 1983; DeKeyser, 1998) have argued for a strong interface (i.e., declarative explicit knowledge can convert into procedural implicit knowledge through practice), supporters of a 'consciousnessraising theory' (e.g., R. Ellis, 1993; N. Ellis, 2005) have discussed in favor of a weak interface position (i.e., explicit knowledge does not convert directly into implicit knowledge, but relatively facilitates its development indirectly by inducing attention to form).

The duality of knowledge in AC-R model is closely related to use-specificity of procedural knowledge as well. Subsequent to the practice of declarative knowledge, the learners incorporate the knowledge into behavioral routines. These routines are very specific rules and can be drawn upon immediately with a low rate of error (DeKeyser, 2007). At the second phase of skill acquisition, the created production rules keep fine-tuning until they become inflexible and use-specific. Any change in the conditions or parameters of practice task is believed to result in 
failing to perform well on post-training tests (Schmidt \& Bjork, 1992). Since the ability to generalize the instructed items to other contexts has been traditionally considered as a major goal of teaching (DeKeyser, 2007; Schmidt \& Bjork, 1992), the extent to which the acquired knowledge can be generalized, as a result of instruction and practice, to other contexts, seems to be of critical importance. This phenomenon, known as" Transfer of knowledge" refers to the way previous leaning influences current and future learning or performance, and the way past or current leaning is applied to similar novel situations (Haskell, 2001; Speelman \& Kirsner, 2005).

The influence of practice has been emphasized by some authors. Ericsson, Krampe, and Tesch-Romer (1993), for instance, claimed that what distinguishes experts from novices is years of effortful, deliberate practice. Yet, in a foreign language context, like Iran, language learners usually do not have the opportunity to be immersed for a long time in a rich target language environment with ample input. Moreover, the results immersion programs have cast doubts on the probability of learning without focused attention to form (e.g. MacFarlane, 2001; Ranta \& Lyster, 2007). In a situation where there is a limited access to input, parallel to cognitive and educational psychologists, second language acquisition researchers are looking for optimal ways to deal with the insufficient time and opportunities for introducing a large amount of practice to learners and have made attempts to manipulate one or more variables in relation to practice tasks (e.g. Farley, 2004; Mystkowska-Wiertelak, 2010; Qin, 2008).

The growing consensus that has emerged from decades of research in SLA is that some kind of practice is required for the knowledge to be integrated into the learners' knowledge system. To investigate which type of practice is more efficient, a group of researchers have endeavored to compare the effect of some input-based practice with that of some output-based. Among this group of researchers, some found similar effect for input and output practice (Farley, 2004; Toth, 2006), others concluded that input practice equally improves comprehension and production (Benati, 2005; Qin, 2008; VanPatten, 2002), and still others found the superior effect of output practice (Erlam, Loewen, \& Philp, 2009; Nagata, 1998a, 1998b). 
Studies in this strand framed their research in sequences which were different from declarative knowledge, practice, and proceduralization sequence. However, in some cases, this sequence has been applied where the researchers initiated the process by providing explicit knowledge and allowed ample practice time for proceduralization to happen.

In spite of the existing body of data confirming the way practice tasks contribute to acquiring some grammatical structures, research in this area suffers from some methodological shortcomings. On the one hand, the findings of the studies obtained under strict laboratory conditions might not have much to offer some implications for realistic ones. On the other hand, most of the studies intending to investigate the effect of practice type applied procedural knowledge tests after a relatively short period of practice phase. In other words, they failed to permit the declarative knowledge to become automatized. The literature shows that the maximum time allocated for practice was 16 hours (DeKeyser, 2007). By failing to utilize discrete measures of declarative and procedural knowledge, even fewer studies have investigated whether the use-specific procedural knowledge is transferrable.

Moreover, most of the studies measure retention after a short interval. This could be one week, 10 days, or three weeks at most. Considering Driskell, Willis, and Cooper's conclusion that: "For a cognitive task that has been learnt, retention tends to dissipate after 5 to 6 weeks" (1992, p.621), and also considering the fact that this time span seems so long that few researchers would observe, the implementation and generalization of the results of studies on the effect of tasks on retention might be under question. The issue has been observed in the present study by administering the delayed posttests 5 weeks after the posttests.

For the purpose of filling the gap in the empirical research on providing declarative knowledge as conducive to the proceduralization of grammatical knowledge, the present study intended to compare the effect of a packet of three output practices with a packet of three input practices on proceduralization and 
transfer of knowledge from one context to another, i.e. production to comprehension and vice versa.

\section{Research questions}

The present study investigated the following research questions:

1. Does the type of practice significantly affect proceduralization of knowledge?

2. Does the type of practice significantly affect knowledge transfer from one context to another?

\section{Method}

\section{Design}

A pretest/posttest/delayed posttest intact group design was employed to compare the effectiveness of two types of form-focused practices, i.e. input and output practice, on the proceduralization of declarative knowledge and transfer of procedural knowledge in English modals' production and comprehension.

\section{Participants}

The participants of the study were 77 Persian adult intermediate male and female freshmen who were learning English as a foreign language at Sheikhbahaee University in Isfahan, Iran. The age of the participants ranged from 18 to 21 . The participants were selected through administration of Oxford Placement Test (OPT), since it is an easy-to-administer, objectively scored test which can be used with any number of students of English to ensure efficient, reliable, and accurate grading and placing of students at different levels (Taylor, 2004).

Six English native speakers, 4 male and 2 female, aged between 32 and 45, and living in-England, Australia, and Canada, took the procedural knowledge tests as well. The native speakers were all educated at the levels ranging from bachelor degree up to the $\mathrm{PhD}$ degree in different academic majors. Since they had already automatized their L1 grammatical knowledge, according to Ellis (2009), the native speakers' performance on the tests of procedural knowledge could help the researchers to determine the time limit needed for the tests. 


\section{Target structure}

A number of factors motivated the choice of modals as the target structure of the present study. A brief review of literature on error analysis revealed that modals are linguistic features which are cross-linguistically problematic for EFL learners and result in errors (Burt \& Kiparsky, 1972). They are non-salient features in that they tend to be unstressed, hence difficult to be noticed in the discourse, and their formmeaning mapping is problematic (Ellis, 2009). Another reason for the selection of modals as the target structure was that the type of structure has been assumed to be a constraining factor for effective form-focused instruction (Ellis, 1994), and previous studies have not investigated how this type of instruction might yield different results from other types of instruction. Moreover, the variety of modals allowed the researchers to present them in a variety of texts for a relatively long period of time in the practice phase of the study.

\section{Instructional materials}

The input tasks which served the goal of the present study were:

1. Focused reading comprehension task: A form-focused reading task for which the input was contrived to include the noticing of predetermined forms (Ellis, 2003). The texts were followed by questions that could be only answered if the participants had successfully processed the target structure. (See Appendix A for a sample of focused reading comprehension task).

2. Focused listening comprehension task: A form-focused task for which the participants listened to a text designed to focus their attention on the structure (Ellis, 2003). The texts were followed by questions that could be only answered if they had successfully processed the target structure. (See Appendix A for a sample of focused listening comprehension task).

3. Error recognition task: A contextualized grammar editing task, proposed by Imao (2001, cited in Brown, 2003), where participants were required to read a text and detect the errors by underlining them (See Appendix A for a sample of error recognition task). The task required the participants to attend to the meaning and form in order to detect the errors. 
The output tasks which served the goal of the present study were:

1. Dictogloss: A structure-based production task proposed by Wajnryb (1990). It required the use of a short text that was selected or devised to have a structural focus. The texts were read at normal speed, two times, sentence by sentence, while the participants noted down key words and phrases. They, then, worked personally to reconstruct it as accurately as possible. (See Appendix B for a sample of dictogloss task).

2. Text-reconstruction task: A structure-based production task proposed by Izumi and Bigelow (2000). It required the participants to read a short passage, enriched with the target structure, and underline the parts they felt to be important for subsequent reconstruction. The passages were then collected and the participants were asked to reconstruct them as accurately as possible. They were then given the chance to compare what they produced with the original text. (See Appendix B for a sample of text-reconstruction task).

3. Corrected close translation (L1-L2): A form-focused task proposed by Cook (2010) which required the participants to produce translation in which they were required to keep the original texts as similar as possible. Then, the participants had the opportunity to compare their texts with the original ones. (See Appendix B for a sample of corrected close translation task).

By and large, the choice of tasks was motivated by the delineation of task dimensions proposed by Willis (1996). The tasks for each experimental group were tried to match those in another group in terms of input, conditions, and processes. For example, the medium of presenting the task, as a key dimension of input, was written for two tasks of the input-group, error-recognition and reading task, and two tasks for the output-group, reconstruction, and translation. The third task, listening for the input-group, and dictogloss for the output-group, had oral medium. It is only the cognitive processes required to perform the output tasks that might make greater demand on the participants in the output-group. This, however, could have been an issue, if the performance of one group on the measures was significantly different from another group. 


\section{Testing materials}

Since the output group received production practice, its performance on the production measure of procedural knowledge, Timed Dual Task Completion Test (TDCOMT) was considered as its ability to acquire/proceduralize this type of knowledge. This group's performance on the comprehension test of procedural knowledge, Timed Dual Task Grammaticality Judgment (TDGJT) was an index of its ability to transfer the acquired knowledge to a different context. For the input group, however, the TDGJT was an index of procedural knowledge and TDCOMT was that of transfer of knowledge. In addition to the timed and dual-task features, both of the tests had structurally irrelevant items to be answered. These features of the tests were decided after Ellis (2009) proposed Time and Focus of Attention as two criteria, among others, which are basic to operationalizing the measurement of implicit and explicit knowledge.

The Timed comprehension/production tests were concerned with the participants' being pressured to perform a task online as opposed to when they have an opportunity to plan their response carefully. In other word, timed criterion was to operationalize the degree to which the knowledge has been proceduralized.

Focus of attention or lack of it was the criterion operationalized in two ways: first, for measuring implicit knowledge, the task required primary focus on meaning, and second, introduction of task duality, requiring the participants to write the number of beep sounds while answering test items, which was adopted from DeKeyser (1997), partly guaranteed that they were deprived of the opportunity to draw upon their controlled processing. The inclusion of fillers as irrelevant items in the timed measures also further guaranteed their focus upon the implicit knowledge.

The TDGJT was a pen-and-paper test consisting of 84 grammatical and ungrammatical items. Twenty eight items were related to the target structure and the remaining items were irrelevant so as to minimize their focus on form. They were asked to underline the wrong part of ungrammatical items. The number of 
irreverent items was decided to be twice as many as the number of target items, as it is common in current literature. The time limit for each sentence was established on the basis of native English speakers' average response time, to which an additional $20 \%$ of the time was added to allow for the slower processing speed of L2 learners (Ellis, 2009). The spent mean time by the native speakers to answer the items of TDGJT was 17.5 minutes. 3.5 minutes were added to this figure $\left(17.5^{*} 0.2=3.5\right)$. The total time to answer the items was 21 minutes. The time allocation for each item was, then, about 15 seconds. However, the items were of unequal length. Therefore, for short items they were given about 10 seconds and for longer ones, they had about 20 seconds to mark the sentences.

The TDCOMT was a 42-item test. It was designed to measure the production of the target linguistic feature.14 items were related to the target structure. The remaining 28 items were related to other grammatical structures so that the participants' attention would be deviated from English modals. The time limit and the irrelevant fillers, together with the duality of tasks, requiring the participants to write the number of beep sound while answering each item, were to make the test a measure of procedural knowledge (DeKeyser, 1997).

Based on the native English speakers' average response time, which was 10.5 minutes, and the additional $20 \%$ time for processing, 20 seconds was allocated for each sentence. The total time for answering the items was about 14.5 minutes. The time allocation for shorter items was about 15 seconds and for longer items 25 seconds.

On the first page, the tests included three example items and five irrelevant fillers. This was due to preventing the participants, who received the tests earlier, from starting answering the items related to the target structure. The researcher asked the participants to turn to the next item after the time allocated to answering each item was over. They were also required to write the number of beep sounds in front of the items while answering each item. 
Internal consistency of the items in each test over three phases of testing was measured as an index of reliability. Cronbach's alpha values for the TDGJT in the pretest, posttest, and delayed posttest were $0.63,0.79$, and 0.81 , respectively. The values for the TDCOMT were $0.6,0.8$, and 0.89 , in pretest, posttest, and delayed posttests, respectively.

\section{Procedure}

Participants in all three groups completed the pretests a week prior to the introduction of treatment to the experimental groups. The classes, then, were randomly assigned to two experimental and one control groups. The experimental groups received explicit instruction on the target structure. All classes were taught by one of the researchers.

In the first session, the instruction was implemented by covering modals and presenting examples to ensure their understanding. The instructor presented the instruction in English and recapped the same materials in Persian to ensure the participants' understanding. The practice sessions were held twice a week for each experimental group in the language laboratory. When the explicit instruction was completed, the participants in the input group received three types of input tasks and the output group received three types of output tasks.

The control group was exposed to the same texts offered for practicing the target feature for the experimental groups. The practice texts were enriched with the target structure, yet the questions or the discussion which followed the text were comprehension questions and did not require their focus on the target structure.This was done to examine the extent to which implicit learning occurred when the explicit knowledge was not presented and their attention was deviated from the target structures.

The practice sessions for the experimental groups and exposure for the control group took about 12 weeks. The posttests were administered the following week. The delayed posttests were administered five weeks after the posttests. In the post and delayed posttests, the completion test was administered prior to the 
grammaticality judgment test. One version of the tests was used over all three testing phases. However, the order of the items of the tests was changed for each test administration.

\section{Scoring and Analysis}

In the TDGJT and TDCOMT, each item was allocated a score of either 1 (if recognized correctly as grammatical or ungrammaticalor completed correctly with appropriate modal) or 0 (if incorrectly recognized as grammatical or ungrammatical or provided with inappropriate modal verb). The mean percentage and standard deviation for each group on pretest, posttest, and delayed posttests were calculated. To answer the research questions, two mixed repeated measures ANOVA, with one between-subject variable (practice type) and one within subject variable (time of test) were run.

\section{Results}

The groups' mean scores on the TDGJ and TDCOM pretests were subject to two independent-samples t-tests. The results revealed that there was no significant difference between the groups' at the initial stage of the study: TDGJT: $t(50)=-$ 1.3, $p=0.2$; TCOMT: $t(50)=1.7, p=0.9$. This indicated that the groups were equivalent in terms of their ability to comprehend and produce the target structure before the experiment. Any difference in the result of post and delayed posttest, then, could be attributed to the effect that instruction and practice might make.

\section{Production test}

Groups' scores on the pretests were subject to a one-way between-group MANOVA to check for the statistical difference between the groups in the initial stage of the study. Preliminary assumption testing was conducted to check for normality, linearity, univariate and multivariate outliers, homogeneity of variancecovariance matrices, and multicollinearity with no violations noted. The results of MANOVA revealed no significant difference among the groups' scores on the pretests: $F(5,140)=1.85, p=0.056$; Wilks' Lambda $=0.78$; partial eta squared $=$ 
0.18. This means that the groups were equivalent in terms of their ability to recognize or produce the target grammatical.

The output group's performance on the TDCOM posttest was an indication of its procedural knowledge, while the control and input group's performance on this test was an index of their ability to transfer the procedural knowledge from the context of comprehension to production. The groups' mean scores and standard deviations on the TDCOM pretest, posttest and delayed posttest are presented in Table 1.

Table 1

Descriptive statistics of the Groups on the TDCOMT

\begin{tabular}{lccccccc}
\hline \multirow{2}{*}{ Groups } & Pretest & \multicolumn{2}{c}{ Posttest } & \multicolumn{2}{c}{ Delayed posttest } \\
\hline \multirow{2}{*}{ Control } & $\mathrm{M}$ & $\mathrm{SD}$ & $\mathrm{M}$ & $\mathrm{SD}$ & $\mathrm{M}$ & $\mathrm{SD}$ \\
\cline { 2 - 7 } Input & 21.9 & 7.8 & 22.3 & 8.1 & 24.6 & 7.4 \\
& 20.4 & 7.7 & 52.8 & 9 & 55.8 & 10 \\
Output & 16.5 & 6 & 57.4 & 10.3 & 62.3 & 11
\end{tabular}

As shown in Table 1, the mean percentage scores of the experimental groups on the TDCOM posttest were better than those of the control group. The figures in the table also indicate that these groups' performance on the delayed posttest was better than that on the pretest, and for the output group, even better than the posttest.

To see whether the difference between the mean scores of the groups on the completion posttest was significant a mixed repeated measures ANOVA was run. (Figure 1 illustrates the results). 


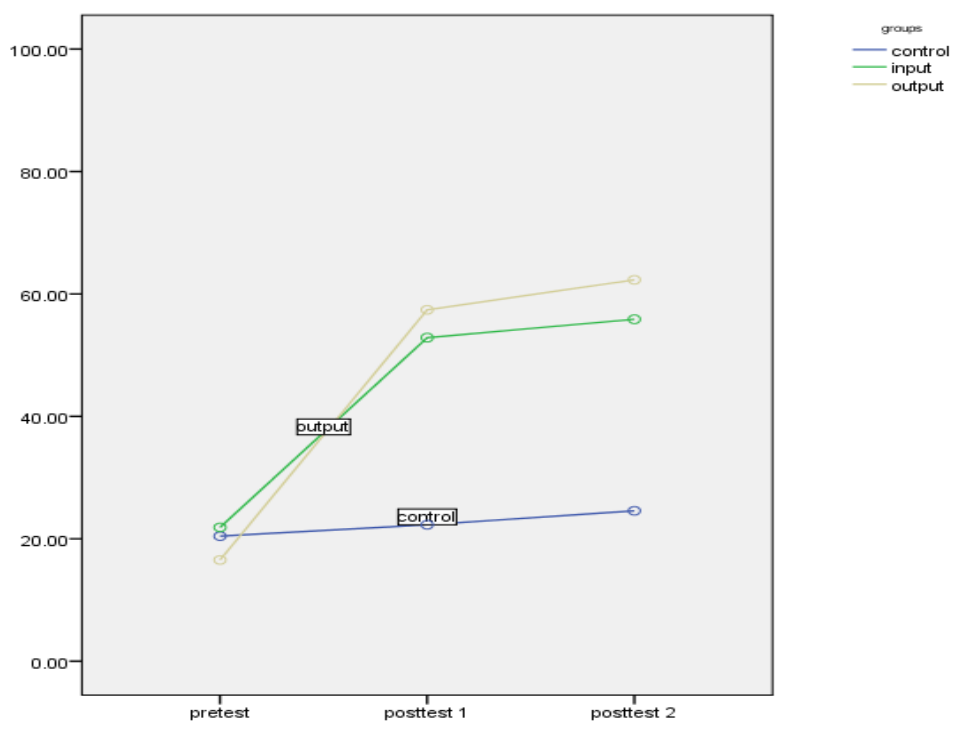

Figure 1

Groups' Performance on the TDCOMT

The statistical analysis found a significant main effect for task type: $F(2,74)$ $=32.98, p=0$, with a moderate effect size (eta squared $=0.5$ ), and time of testing: $F$ $(2,73)=107, p=0$, with a large effect size (eta squared $=0.8)$. There was also a significant interaction effect between time of testing and task type: $F(4,146)=$ 23.9, $p=0$, with a moderate effect size. A post hoc analysis revealed that the performance of the experimental groups differed significantly from the control group on the posttest and delayed posttest. However, there was no significant difference between the input and output groups on the posttest and the delayed posttest.

\section{Comprehension test}

The output group's performance on the TDGJ posttest would be an indication of its ability to transfer knowledge from production to comprehension context, while the control and input groups' performance on this test would be an index of their ability 
to proceduralize the implicit knowledge. The groups' mean scores and standard deviations on the TDGJ pretest, posttest and delayed posttest are presented in Table 2 .

Table 2

Descriptive Statistics of the Groups on the TDGJT

\begin{tabular}{lcccccc}
\hline \multirow{2}{*}{ Groups } & \multicolumn{2}{c}{ Pretest } & \multicolumn{2}{c}{ Posttest } & \multicolumn{2}{c}{ Delayed posttest } \\
\hline & $\mathrm{M}$ & $\mathrm{SD}$ & $\mathrm{M}$ & $\mathrm{SD}$ & $\mathrm{M}$ & $\mathrm{SD}$ \\
\cline { 2 - 7 } Control & 45.7 & 10.3 & 49.2 & 8.9 & 43.1 & 12.7 \\
Input & 43.1 & 8 & 72.7 & 8.5 & 49.5 & 7 \\
Output & 50 & 10 & 72.2 & 7 & 74.3 & 8
\end{tabular}

As shown in Table 2, the mean percentage score of the experimental groups on the TDGJ posttest exceeded that of the control group. The figures also indicate that while the input group's performance on this test receded, the output group was able to maintain its level of performance over time.The table also shows that the control group's performance on the post and delayed posttests did not improve markedly.

To see whether the difference between the mean percentages of the groups was significant on posttest and delayed posttest, a repeated-measures ANOVA was run (Figure 2 illustrates the results). 


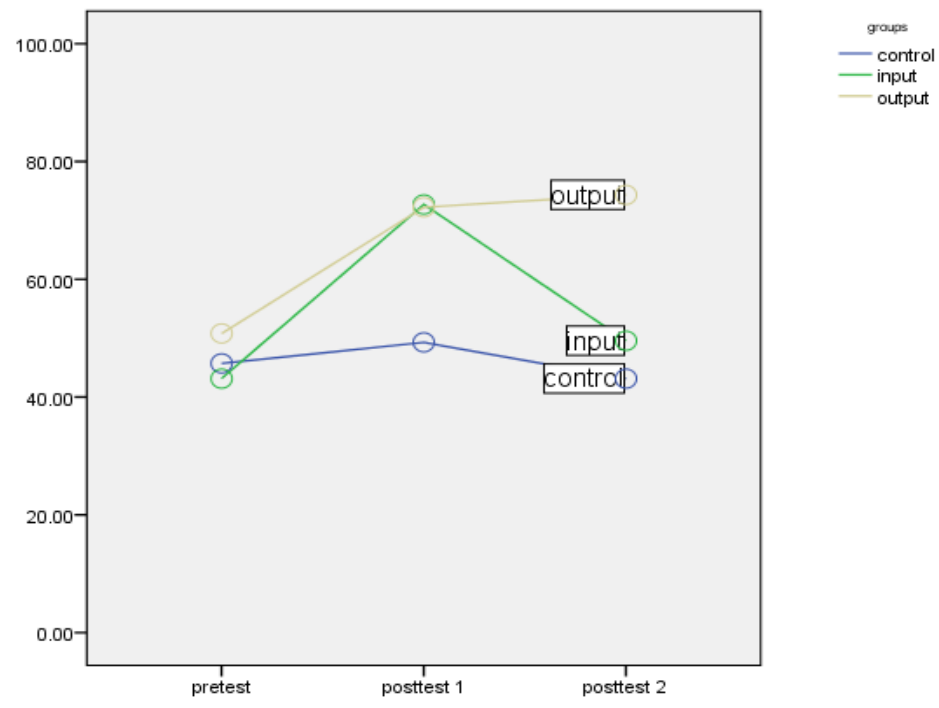

Figure2

Groups' Performance on the TDGJT

As shown in the figure, the repeated measure ANOVA found a statistically significant effect for time of testing: $F(2,74)=5.7, p=0.005$, with a small effect size (eta squared $=0.13$ ), task type: $F(2,74)=53, p=0$, with a moderate effect size (eta squared $=0.6$ ), and an interaction effect between testing time and task type: $F$ $(1,75)=46.5, p=0$, with a small effect size (eta squared $=0.4)$. A post hoc analysis revealed that both experimental groups significantly outperformed the control group on the posttest. However, on the delayed posttest, the input group's performance decreased and there appeared a significant difference between the input and the output group in the delayed posttest. On this test, the input group did not differ significantly from the control group. But, the input group's performance was still significantly better on the delayed posttest than on the pretest. On the delayed posttest, the output group, however, did not perform significantly different from the posttest. 


\section{Discussion}

A major goal of the present study was to investigate whether explicit instruction of structures followed by a packet of three input or output practices would contribute to proceduralization of knowledge. It also intended to compare the effects of input practice with those of output practice on proceduralization and transfer of knowledge on English modals.

What was observed from the output group's performance on the TDCOMT and the input group's performance on the TDGJT revealed that consciously learned explicit knowledge might be used under time pressure and unfocused attention to form. Performing dual tasks simultaneously under time pressure together with the inclusion of distracters of ample proportion is assumed to expose the participants to the situation where their access to declarative explicit knowledge is far from perfect.

The descriptive statistics in Tables 1 and 2 showed that practice of different types enabled the integration of the declarative knowledge into interlanguage system. The results indicate that on the measures of proceduralized/implicit knowledge, where the participants' attention was distracted from the target structure through time pressure, dual-tasks, and irrelevant items, the experimental groups were able to process and produce the target structure. As far as the production skill is concerned, the output group's improvement, in their production skill on theTDCOM posttest was not contrary to the researchers' expectation, since the main purpose of output practice was for the learners to acquire the declarative knowledge and proceduralize it through production tasks.The same is true for the comprehension skill of the input group, except that comprehension practice was intended to enable the participants in this group to proceduralize the declarative knowledge through input practice. Thus, explicit instruction on the rules and function of English modals followed by three types of input or output practices significantly contributed to their language development by helping them absorb the target structure and proceduralize the related knowledge. The result of this group can be interpreted in light of Swain's Output hypothesis (Swain, 1985). This 
hypothesis suggests that language production can facilitate language acquisition if it ensures processes such as noticing, hypothesis testing, syntactic processing, and metalinguistic reflection. For Swain (1985), production entails the activation of those cognitive processes that result in restructuring of the developing linguistic system.

Levelt's (1989) speech production model might also help us interpret the results. Output practice can be hypothesized to give the participants opportunities to conceptualize, formulate, and articulate materials when they are engaged in the tasks encouraging them to convey message relying on their existing linguistic knowledge for language production. Task-based language performance also requires high rates of noticing and attention to L2 structures and thus strongly accounts for learning as proposed by cognitive hypothesis (Schmidt, 1983, 2001). This is confirmed by comparing the result of input group with that of the control group which failed to perform significantly better on comprehension test of procedural knowledge. In accordance with this, the learners' noticing the forms is necessary for the knowledge to integrate into their developing linguistic system. As Schmidt (2012) has noted: "Learning, establishing new or modified knowledge, memory, skill, and routines is therefore, largely, and perhaps exclusively, a side effect of attended processing" (p. 4).

The performance of the control group on the TDGJ posttest as an index of procedural knowledge showed that implicit learning is impossible if the learners are merely exposed to limited number of examples of the target feature and much more exemplars are needed, or at least some degree of attention is required to integrate the linguistic items into the interlanguage.

The results are at variance with non-interface position which claimed that consciously learned explicit knowledge might not be used under time pressure and unfocused attention to form. Belonging to non-interface camp, Hulstijn (2002) and Paradise (2004), have noted that implicit and explicit linguistic systems are independent, so that whatever learned consciously might not be used under the conditions that draw upon implicit knowledge and the knowledge acquired 
unconsciously fails to be verbalized or used consciously. The result of the present study is also incompatible with what Williams \& Kuribara (2008) found as evidence for implicit learning, where the participants were merely exposed to examples of the canonical sentence pattern and scrambled clauses, an optional structure that moves a phrase in the direction of the head.

This result, however, confirms DeKeyser's strong interface position in that explicit knowledge can be converted into implicit through practice. This confirms that, in the course of acquisition, the nature of linguistic knowledge changes so that it becomes more increasingly available for speeded situations, i.e. the development of second language knowledge is a process of proceduralizing explicit knowledge into implicit.

As to the issue of "Transfer of Knowledge", it was found that providing learners with explicit knowledge and a variety of input or output form-focused practice enable them acquire the skill to produce and interpret the target structure. The output group's performance on the TDGJT of comprehension indicates that the participants were able to transfer their procedural knowledge from production context, in which they practiced their declarative knowledge, to the reverse context of comprehension. The input group also succeeded in using and transferring its procedural knowledge to the reverse context of production. The control group, on the other hand, did not improve its performance on the production test of procedural knowledge. Looking at Table 2 would indicate that the group was unable to interpret the target features under time pressure either.

The results, therefore, cast doubt on the legitimacy of use-specificity of knowledge as a principle of ACT-R theory of skill acquisition. If use-specificity of knowledge is taken as a proved principle, and if the knowledge measured through the instruments of the present study was procedural knowledge, the results of knowledge transfer can be accounted for by resorting to findings of educational psychology. Although the present study did not introduce practice variety as a variable and three types of input/output practices were offered to stimulate the learners' interest during the relatively long period of practice phase, the researchers 
found that introducing a variety of three form-focused tasks as practice in the study has apparently provided opportunities to make form-meaning relationships clear enough to allow the learners transfer the acquired knowledge to the reverse context. The result is compatible with the findings in the domain of cognitive and educational psychology where the cognitive psychologists, such as Anderson and Shunn (2000), Schmidt and Bjork (1992), and Speelman and Kirsner (2005) recommended that introducing variation among versions of tasks to be practiced might help the learners generalize their acquired knowledge in the post-training phase to novel situations. Previous studies (DeKeyser, 1997; DeKeyser \& Sokalski, 1996), which introduced one input or output task as treatment, showed a partial lack of knowledge transfer to new contexts. Variety in tasks during the practice phase of learning brings more general skill, according to Speelman and Kirsner (2005) since it develops efficient adaptation to a task environment. If the learners are exposed to no or small task variation, they will merely develop skills to cope with that limited environment. If, on the other hand, the practice environment involves task variety, even tasks of the same nature, the learners learn how to cope with the variation. Under this circumstance, they rely more on the abstraction of features common to many task situations. Therefore, they would develop the required skill to deal with a variety of situations. Anderson and Shunn (2000) attribute knowledge transfer to "understanding", which is basically nothing more than having enough knowledge about a concept that can be used flexibly for solving problems which involve the concept. This study has, therefore, confirmed the constructive role of practice and its variety in transferring the knowledge across contexts. The tests employed time pressure, task duality, and irrelevant items to reduce the possibility of the participants monitoring interpretation or production and merely drawing on their declarative knowledge.

Knowledge transfer, known as transfer of training in educational psychology, has also been addressed by Schmidt and Bjork (1992). They hold that introducing some difficulties for the learner can improve acquisition as well as retention: "Educators in general and language teachers in particular can induce variation among versions of the tasks to be practiced, with the focus on a criterion of 
generalizability"(p. 210). Cognitive psychologists have found that in order for the training of a complex cognitive task, like language learning and use, to be transferable to a new context, construction of a cognitive structure is inevitable. This enables the learners to recognize those particular operations required to reach a solution in the new context. Ranzijn (1991) and Shapiro and Schmidt (1982) pointed out that by introducing variety into practice type, the construction of cognitive structures and, consequently, transfer of acquired skill are enhanced because variety increases the chances that common features can be identified and that relevant features can be distinguished from irrelevant ones.

Comparing the participants' performance on the TDCOM posttest with that of the delayed posttest, it was found that the outperformance of the participants did not disappear, so that they have retained what they have acquired. Although it cannot be certainly maintained that the knowledge the participants drew upon was implicit/procedural, it is evident that the speed of access to the declarative knowledge benefited the participants after a time span of 6 weeks.

The results of this study, therefore, suggest that, when providing practice of different nature is not possible due to some institutional constraints and time limitation, introducing practice of one type might help learners proceduralize their knowledge and transfer it to the relatively dissimilar context, provided that the teacher introduces variety in the practice tasks. One may find the results of the present study unpractical in real context of foreign language teaching in that few institutional contexts, if any, would provide the opportunity to practice each linguistic item for such a long period of time. However, achievements are brought at the expense of devotion of more time and energy. The unsatisfactory results of teaching in foreign language classrooms call for more spiral syllabi where the items are covered more than once, twice, or even three times. This enables the items to be treated at different times with different levels of complexity. 


\section{Conclusion}

The findings of the present study confirm that comprehension or production practice develops production as well as comprehension skills at the same time. Although the results of this study and studies of the same nature might not guarantee that the knowledge was surely proceduralized, they confirm what DeKeyser and Juffs (2005) stated about the speeded availability of explicitly acquired knowledge which can be viewed as precious. While achieving this knowledge is not the ultimate goal of language acquisition, it can be viewed as an intermediate goal on the path to spontaneous language use. The consensual goal of language learning is effortless automatic use of language. However, automatic use by itself does not exclude the possibility of declarative knowledge accessibility (DeKeyser, 2007). Given the skill-specificity of knowledge, availability of speeded declarative knowledge, or at least partially acquired proceduralized knowledge can enable learners to generalize it to dissimilar contexts. The pedagogical implication of the study is that depending on the institutional ecological situations, the practice can be devised of one type over a relatively long time. Another implication is that at least for some structures, like English modals, for which the mapping of formmeaning relationship is not evident, variety in practice of the same nature would lead to proceduralization and knowledge transfer.

It should be pointed out that some limitations existed in the process of conducting the study. To measure the effect of practice on the procedural knowledge, as a cognitive construct, the valid instrument would be a free production test. However, the target structure was less amenable to this type of test. Designing a test in which a target structure, like modals, can be elicited to occur in obligatory context was very difficult, if not impossible.

\section{Notes on Contributors:}

Mehrnoosh Fakharzadeh is an assistant professor of Applied Linguistics at Sheikhbahaee University. She teaches BA and MA courses in translation. Her areas of interest include psycholinguistics, pragmatics, and translation studies. 
Manijeh Youhanaee holds a $\mathrm{PhD}$ in Language and Linguistics from the University of Essex. She has co-authored with Badrizadeh "A Descriptive Dictionary of Theories of Generative Grammar". She has published a number of articles on the teaching/ acquisition of different English syntactic properties by native speakers of Persian. She teaches MA and $\mathrm{PhD}$ courses in linguistics, generative grammar, TEFL and SLA. Her areas of interest include syntactic theory, acquisition of L2 \& L3 syntax, and issues in teaching and learning English as a second/foreign language.

\section{References}

Anderson, J. R. (1983). The architecture of cognition. Cambridge, MA: Harvard University Press.

Anderson, J. R. (2000). Cognitive psychology and its implications. New York: Worth Publishers.

Anderson, J, R., \& Lebiere, C. (1998). The atomic component of thought. Mahvah, NJ: Erlbaum.

Anderson, J.R., \& Shunn, C. D. (2000). Implications of the ACT-R learning theory: No magic bullets. In R, Glasser (Ed.), Advances in instructional psychology (pp.1-33). Mahwah, NJ: Erlbaum.

Benati, A. (2005). The effects of processing instruction, traditional instruction and meaning-output instruction on the acquisition of the English past simple tense. Language Teaching Research, 9, 67-93.

Brown, H. D. (2003). Language assessment: Principles and classroom practices. White Plains, NY. Pearson Education: Longman.

Burt, M., \& Kiparsky, C. (1972). The Gooficon: A repair manual for English. Rowley, MA: Newbury House.

Cook, G. (2010). Translation in language teaching. Oxford: Oxford University press.

DeKeyser, R.M. (1995). Learning second language grammar rules: an experiment with a miniature linguistic system. Studies in Second Language Acquisition, $17,379-410$. 
DeKeyser, R. (1997). Beyond explicit rule learning: Automatizing second language morphosyntax. Studies in Second Language Acquisition, 19(2), 195-221.

DeKeyser, R.M. (1998). Beyond focus on form: Cognitive perspectives on learning and practicingsecond language grammar. In C. Doughty, \& J. Williams (Eds.), Focus on form in classroom second language acquisition (pp.42-63). Cambridge: Cambridge University Press.

DeKeyser, R.M. (2007). Practice in a second language: Perspectives from applied linguisticsand cognitive psychology. Cambridge: Cambridge University press.

DeKeyser, R.M. (2003). Cognitive-Psychological Processes in Second Language Learning. In C. Doughty, \& M. Long (Eds.), The handbook of second language acquisition (pp. 119-138). Malden, MA: Blackwell.

DeKeyser, R. M., \& Juffs, A. (2005). Cognitive considerations in L2 learning. In E. Hinkel (Ed.), Handbook of research in second language teaching and learning (pp. 437-454). Mahvah, NJ. London: Lawrence Erlbaum associates.

DeKeyser, R., \& Sokalski, K. (1996).The differential role of comprehension and production practice. Language Learning, 46 (4), 613-642.

Dornyei, Z. (2009). The psychology of second language acquisition. Oxford: Oxford University Press.

Driskell, J. E., Willis, R. P., \& Cooper, C. (1992). Effect of overlearning on retention. Journal of Applied Psychology, 77, 615-622.

Ellis, N. (1994). Introduction: Implicit and explicit language learning-an overview. In N. Ellis (Ed.), Implicit and explicit language learning, (pp. 1-31). San Diego, CA: Academic Press.

Ellis, N. C. (1995). The Psychology of Foreign Language Vocabulary Acquisition: Implications for CALL. International Journal of Computer Assisted Language Learning (CALL). Special Issue on Cognitive Aspects of Second Language Acquisition.

Ellis, N. (2005). At the interface: dynamic interactions of explicit and implicit knowledge. Studies in Second Language Acquisition, 27, 164-194.

Ellis, R. (1993). Second language acquisition and the structural syllabus. TESOL Quarterly. 27, 91-113. 
Ellis, R. (2002). Does form-focused instruction affect the acquisition of implicit knowledge? Studies in Second Language Acquisition, 24(2), 223-236.

Ellis, R. (2003). Task-based Language Learning and Teaching. Oxford: Oxford University Press.

Ellis, R. (2009). Measuring implicit and explicit knowledge of a second language. In R. Ellis, S. Loewen, C. Elder, R. Erlam, J. Philp, \& H. Reinders (Eds.), Implicit and explicit knowledge in second language learning, testing and teaching (pp.31-64). Bristol, Buffalo, Toronto. Multilingual Matters.

Erlam,R., Loewen, S. \& Philp, R. (2009). Implicit and explicit corrective feedback and the acquisition of L2 grammar. In R. Ellis, S. Loewen, C. Elder, R. Erlam, J. Philp, \& H. Reinders (Eds.), Implicit and explicit knowledge in second language learning, testing and teaching. (pp. 303-332). Bristol, Buffalo, Toronto. Multilingual Matters.

Ericsson, K. A., Krampe, R.T., \& Tesch-Romer, C. (1993). The role of deliberate practice in the acquisition of expert performance. American Psychologist, 100, 363-406.

Farley, A. P. (2004). Processing instruction and the Spanish subjunctive: Is explicit informationneeded? In B. VanPatten (Ed.), Processing instruction: Theory, research, and commentary (pp. 227-239). Mahwah, NJ: Lawrence Erlbaum.

Haskell, R. E. (2001). Transfer of Learning: Cognition, Instruction, and reasoning. New York: Academic press.

Hulstijn, J. (2002). Towards a unified account of the representation, processing and acquisition of second language knowledge. Second Language Research, $18,193-223$.

Izumi, S., \& Bigelow, M. (2000). Does output promote noticing and second language acquisition? TESOL Quarterly, 34, 239-78.

Johnson, K., \& Johnson, H. (1998). Encyclopedic Dictionary of Applied Linguistics. Blackwell Publishers. Malden, Massachusetts.

Krashen, S. (1981). Second language acquisition and second language learning. London: Pergamon.

Levelt, W. (1989). Speaking: From intention to articulation. Cambridge, MA: Newbury House. 
Long, M. H. (1991). Focus on form: A design feature in language teaching methodology. In K. DeBot, R. Ginsberg, \& C. Kramsch (Eds.), Foreign language research in cross-cultural perspective (pp. 39-52). Amsterdam, Netherlands: John Benjamins.

MacFarlane, A. (2001). Are brief contact experiences and classroom language learning complementary? Canadian Modern Language Review, 58, 64-83.

Mystkowska-Wiertelak, A. (2010). Production-oriented and reception-based approaches to teaching English grammar: An empirical study. (Doctoral Dissertation). Available from http://hdl.net/10593/269.

Nagata, N. (1998a). Input vs., output practice in educational software for second language acquisition, Language Learning and Technology, 1 (2), 23-40.

Nagata, N. (1998b). The relative effectiveness of production and comprehension practice in second language acquisition. Computer Assisted Language Learning, 11 (2), 153-177.

Paradis, M. (2004). A Neurolinguistic Theory of Bilingualism. Amsterdam: John Benjamins.

Qin, J. (2008). The effect of processing instruction and dictogloss tasks on acquisition of the English passive voice. Language Teaching Research, 12 (1), 61-82.

Ranta, L. \& Ryster, R. (2007). A cognitive approach to improving immersion students' oral language abilities: The awareness- practice- feedback sequence. In R. M. DeKeyser (Ed.), Practice in a second language: Perspectives from applied linguistics and cognitive psychology (pp.141160). Cambridge: Cambridge University Press.

Ranzijn, F.J.A. (1991). The number of video examples and the dispersion of examples as instructional design variables in teaching concepts. Journal of Experimental Education, 59,320-330.

Schmidt, R. (1983). Interaction, acculturation and the acquisition of communication competence. In M. Wolfson, \& E. Judd (Eds.), Sociolinguistics and second language Acquisition (pp.202-226). Rowley, MA: Newbury House. 
Schmidt, R. (2001). Attention. In P. Robinson (Ed.), Cognition and second language instruction (pp.3-32). Cambridge: Cambridge University Press.

Schmidt, R. (2012). Attention, awareness, and individual differences in language

learning. In W. M. Chan, K. N. Chin, S. Bhatt, \& I. Walker (Eds.), Perspectives on individual characteristics and foreign language education (pp.27-50). Boston,

MA: Mouton de Gruyter.

Schmidt, R. A., \& Bjork, R. A. (1992). New conceptualizations of practice: Common principles inthree paradigms suggest new concepts for training. Psychological Science, 3(4), 207-17.

Segalowitz, N. (2005). Automaticity and second languages. In C. Doughty \& M. Long (Eds.), The handbook of second language acquisition (pp. 382-408). Malden, MA: Blackwell.

Shapiro, D. C., \& Schmidt, R. A. (1982).The schema theory: Recent evidence and developmental implications. In J. A. S. Keiso, \& J. E. Clark (Eds.), The development of movement control and co-ordination (pp., 113-150). New York: Wiley.

Spada, N. (2007). Communicative language teaching: current status and future prospects. In J. Cummins, \& C. Davison (Eds.), International handbook of English language teaching (pp. 271-88). New York: Springer.

Speelman, C. P., \& Kirsner, K. (2005). Beyond the Learning Curve: The construction of mind.Oxford: Oxford University Press.

Swain, M. (1995). Communicative competence: Some roles of comprehensible input and comprehensible output in its development. In S. Gass, \& C. Madden (Eds.), Input in second language acquisition (pp. 235-253). Cambridge, MA: Newbury House.

Taylor, L. (2004). Issues of Test Comparability, Research Notes 15, 2-15.

Toth, P. D. (2006). Processing instruction and a role for output in second language acquisition. Language Learning, 56, 319-385.

VanPatten, B. (1996). Input processing and grammar instruction: Theory and research. Norwood, NJ: Ablex.

VanPatten, B. (2002). Processing instruction: An update. Language Learning, 52, 755-803. 
VanPatten, B. (2003). From input to output: A teacher's guide to second language acquisition. New York: McGraw-Hill.

VanPatten, B., \& Sanz, C. (1995). From input to output: Processing instruction and communicativetasks. In F. Eckman, D. Highland, P.W. Lee, J. Milcham, \& R. R. Weber (Eds.), Second language acquisition theory and pedagogy. (pp. 169-186). Mahwah, NJ: Lawrence Erlbaum Associates.

Wajnryb, R. (1990). Grammar dictation. Oxford: Oxford University Press.

Williams, J. N., \& Kuribara, C. (2008). Comparing a nativist and emergentist approach to the initial stage of SLA: An investigation of Japanese scrambling. Lingua, 118, 522-553.

Willis, J. (1996). A Framework for Task-Based Learning. Harlow: Longman.

\section{Appendix A: Samples of tasks in the output group}

\section{Dictogloss}

My friend Dona cannot say "no". If another student asks her, "May I ask for your pen?" she always says, "Of course, you can, and hands it over, even when she only has one pen and it means she cannot do her work. After I heard she did that one day, I told her that she can say 'Sorry, but you cannot, because I only have one pen' in reply, she said, 'But how are they able to do their work without a pen?' I knew that I could have tried to answer that question, but somewhat I did not think I had the ability to change how she behaved, no matter what I said.

\section{Text reconstruction task}

My sister used to live in Montana, and when I visited her, we would go on weeklong backpacking trips in the mountains. Every morning we would wake up to the sound of singing birds. During the day, we would hike through woods and along mountain streams. Often we would see deer. Once we saw a bear, but it went off in the opposite direction. 


\section{Corrected close translation}

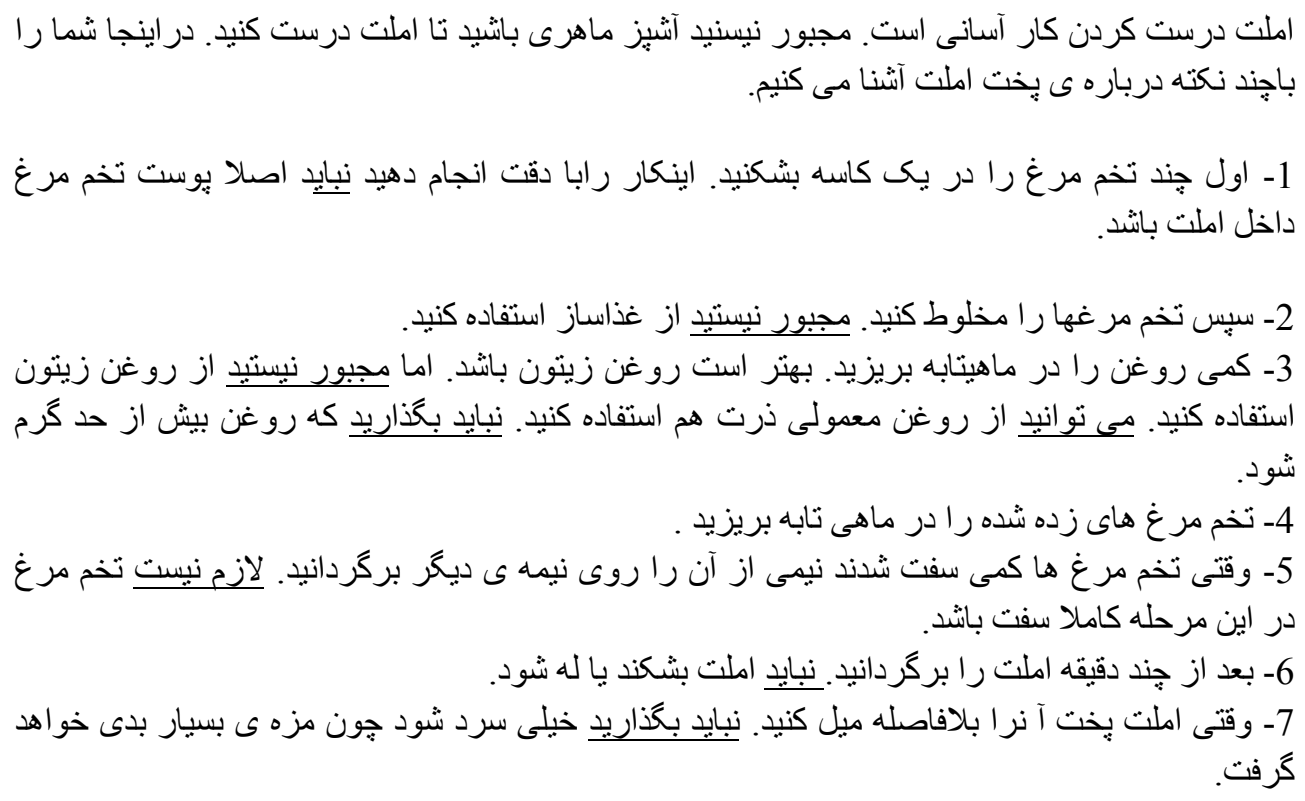

\section{Appendix B: A sample of text for the input/control group}

\section{Focused reading comprehension}

A sergeant reminded us that we must not deal with a burglar if he enters our home, because it might be dangerous. He also reminded us that according to law we are required to inform the police about key holders after a break- in. A man reported that two days ago he had been burgled in the afternoon. The thief probably entered through an open window, although at that time of the day there must have been plenty of people around who witnessed the breakin. If you saw anything, you should report it to the police.

1. It is necessary to tackle a burglar yourself. 
2. You can be in danger by facing a thief.

$\mathrm{T} F$

3. One does not have to give information about key-holders.

$\mathrm{T} \quad \mathrm{F}$

4. The thief must have entered through the window.

$\mathrm{T} \quad \mathrm{F}$

5. The writer is less that $50 \%$ sure that there were lots of people around in that afternoon. $\mathrm{T} \quad \mathrm{F}$

\section{Focused listening comprehension}

Making an omelet is easy. You don't have to be a great chef to do it.

Here are some basic instructions:

-First, break some eggs into a bowl. Break them carefully. You must not let any of the shell get into the omelet.

-Next, mix up the eggs. You don't have to use a special food

processor- mixing them with a fork can be fun.

-Then, heat some oil in a pan. Olive oil is best, but you don't have to use olive oil. You can use ordinary corn oil if you want. You must not let the oil get too hot, or it will start to burn.

-Pour the egg mixture into the pan, and mix it a little.

\section{Error recognition task}

My sister lived in Montana, and when I was visiting her, we would go on weeklong backpacking trips in the mountain. Every morning we woke up to the sound singing birds. During the day, we used to hike through woods and along mountain streams. Often we saw deer. Once we used to see a bear, but it went off the opposite direction. 